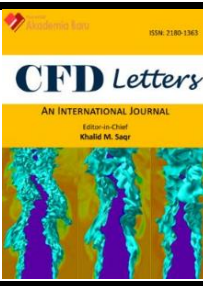

\title{
Computational Fluid Dynamics (CFD) Study on the Effect of the Number of Blades on the Performance of Double-Stage Savonius Rotor
}

\author{
Muhammad Syahmy Mohd Halmy ${ }^{1}$, Djamal Hissein Didane ${ }^{2,}{ }^{*}$, Lukmon Owolabi Afolabi $^{2}$, Sami Al- \\ Alimi $^{1}$ \\ 1 Department of Mechanical Engineering, Faculty of Mechanical and Manufacturing Engineering, Universiti Tun Hussein Onn Malaysia, 86400 \\ Parit Raja, Batu Pahat, Johor, Malaysia \\ 2 Center for Energy and Industrial Environment Studies, Universiti Tun Hussein Onn Malaysia 86400 Parit Raja, Batu Pahat, Johor, Malaysia
}

\section{ARTICLE INFO}

\section{Article history:}

Received 16 February 2021

Received in revised form 14 March 2021

Accepted 15 March 2021

Available online 11 April 2021

\section{ABSTRACT}

Wind energy is known as renewable energy with the properties of the free, abundant and readily available source of energy. Wind power has now been seen as an alternative way to generate electricity. However, the existing wind turbines to harness this energy, which is used to transform wind kinetic energy into electricity still suffer low conversion capabilities. This study is therefore set out to evaluate the performance of a double-stage Savonius-type rotor while aiming to examine the effectiveness of this technique in increasing the efficiency while overcoming the inherent low inefficiency of the Savonius rotor. The simulations involved the use of the K-omega SST as the turbulent viscosity model. Three simulation models based on a different number of blades on the double-stage model are tested in terms of torque, power, torque coefficient and power coefficient. It is concluded that the double-stage technique was capable of enhancing the performance of the Savonius rotor. It was observed that more blades on a double-stage rotor have a negative effect on the performance of the Savonius rotor in terms of both torque efficiency and power efficiency. Comparing the three models, it was found that the two-blade model of the double-stage produced more torque and power output compared to the other three-blade and four-blade models of the double-stage Savonius rotor. Furthermore, the highest conversion efficiency in terms of power among all models occurs at the TSR of 0.6 with a corresponding maximum power coefficient of $18.4 \%$.

\section{Introduction}

Non-renewable energy comes from sources that will run out in thousands or even millions of years. Most sources of non-renewable energy are fossil fuels. Fossil fuels were created as marine creatures' remains decayed millions of years ago, under vast amounts of pressure and heat [1]. Most fossil fuels are burned to generate energy and electricity. Burning fossil fuels is harmful to the environment. When coal and oil are burned, they release particles that pollute the air, water, and land $[2,3]$. Therefore, using renewable energy is the solution to avoid this pollution problem. Renewable energy is classified as a clean source of energy to reduce global emissions. Wind energy

\footnotetext{
* Corresponding author.

E-mail address: djamal@uthm.edu.my (Djamal Hissein Didane)
} 
is one of the potentials used. It is a type of solar energy that its harnessing does not pollute the environment as much as fossil fuels, coal and nuclear power plants [4,5]. It is abundant, renewable, widely distributed, clean, and produces no greenhouse gas emissions during operation as an alternative to fossil fuels. The cost per unit of energy produced is similar to the cost of new coal and gas installations [6]. Sustaining sustainability is vital to use this renewable energy.

A wind turbine is a device that converts kinetic energy from the wind into electricity. The blades of a wind turbine turn at a constant or variable velocity between 13 and 20 revolutions per minute, depending on their technology. The velocity of the rotor varies with the wind's velocity to achieve greater efficiency [7]. This wind turbine extracts the wind energy into the electrical power and supplies it to the industrial and residential areas. There are nowadays many varieties of wind turbines, such as the horizontal axis wind turbine (HAWT) and the vertical axis wind turbine (VAWT). The HAWT is widely used but it requires a strong wind flow rate $[8,9]$. The VAWT comprises two types known as Savonius wind turbine and Darrieus wind turbine [10]. VAWTs are also gaining more popularity nowadays as wind energy converters given the fact that they can generate power even at relatively low wind speeds compared to HAWTs. The Darrieus turbine uses the lift force generated by the blade, whereas the Savonius turbine exploits the drag force [11]. In general, VAWTs have more advantages compared to HAWTs. They could easily be installed on the rooftop of buildings as they can receive the wind from different directions and while handling the turbulent conditions in the urban areas. VAWTs emit less noise due to their lower rotational speed, which can be a problem for residential populations and require fewer components [12]

The Savonius-type VAWT is popular because it is quiet, simple and requires minimal maintenance. It is also independent of the wind direction and has a good starting torque at especially at lower wind speeds [13]. This type of VAWT consists of two halves of cylinders. The two semi-cylinders move sideways along the cutting plane that looks like the letter $\mathrm{S}$. The lower blade catches the wind and forces the blade to rotate around its central vertical shaft. In contrast, the upper blade hits the blade and causes the wind to be deflected sideways around it [14]. However, the Savonius rotor with twisted blades shows better potentials in terms of smooth running, higher efficiency and self-starting capability compared to the semicircular bladed rotor [15]. The number of blades in the Savonius wind turbine has a significant impact on the efficiency and performance of the wind turbine's operating system. The power coefficient decreases due to the increase in the number of blades $[16,17]$. This is because the increasing blade numbers reduces the torque difference between the concave and convex sides when the convex area increases, which eventually affects the coefficient of power. The Savonius wind turbine with a multi-blade could help to enhance the torque characteristics. As the number of blades increases, changes in a Savonius rotor's dynamics and static moment decrease along with the advancing bucket's angular positions. As both designs of VAWTs suffers from inherent low inefficiencies, many efforts have been exerted over the years to enhance their performances [18, 19]. Among the renowned technique is the dual-stage design of the wind turbine which can be applied to overcome this inefficiency while working efficiently under low wind speed conditions [20].

Thus, in this study, the dual-stage concept is used on a Savonius design of VAWT while aiming to establish the characteristics of a multi-stage in enhancing the performance of the Savonius wind turbine using a multi-stage configuration.

\section{Methodology}

\subsection{Simulation Model}

The Savonius rotor was used to develop the simulation models. The Savonius design chosen is a double-stage design which means that it has one stage of blades at the top layer and another at the 
bottom layer. Although there are two layers of blades, only one rotor is used to mount the two layers to rotate the double-stage models. However, the top and bottom blades are designed to face the opposite direction to accommodate wind from different directions. Three configurations are considered using the multi-stage technique. The dimension of the blade for all configurations is the same and the only difference is the number of blades.

At each stage of the rotors, these models are equipped with two blades in the first configuration, three blades and four blades in the second and third configuration, respectively, as shown in Figure 1. Thus, the first design comprises four blades in total (two at the top and two at the bottom) and the second design comprises six blades, while the last design comprises eight blades in total, as shown in Figure 1. The blades are C-shape design with each blade has a dimension of $70 \mathrm{~cm}$ of height, $70 \mathrm{~cm}$ rotor diameter, and $0.01 \mathrm{~cm}$ end plate thickness. The direction of blades at both the top stage and bottom stage of the rotor is set in opposing directions in order to increase the rate of receiving the incoming wind from any direction.

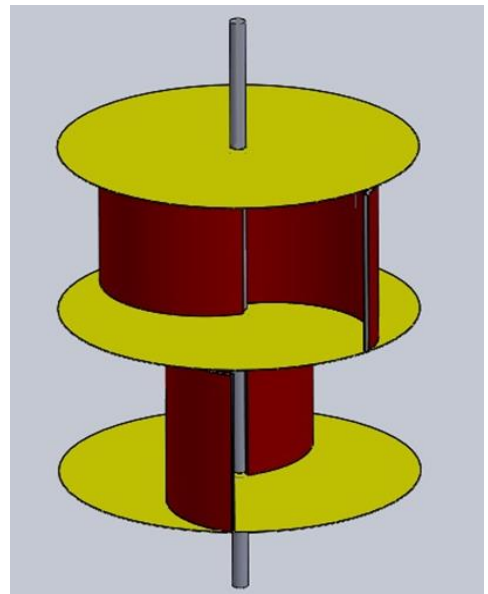

(a)

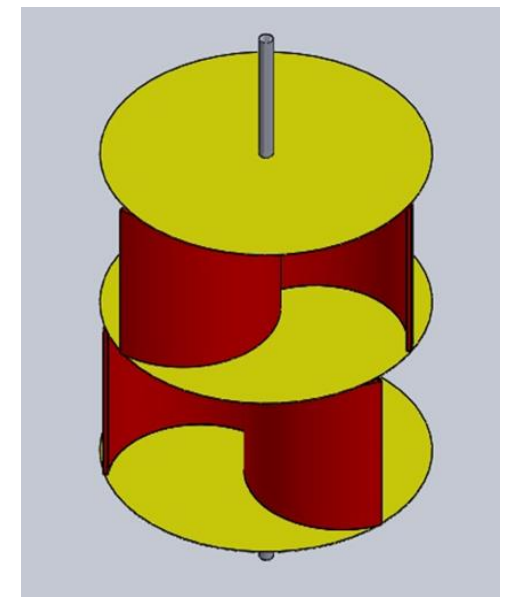

(b)

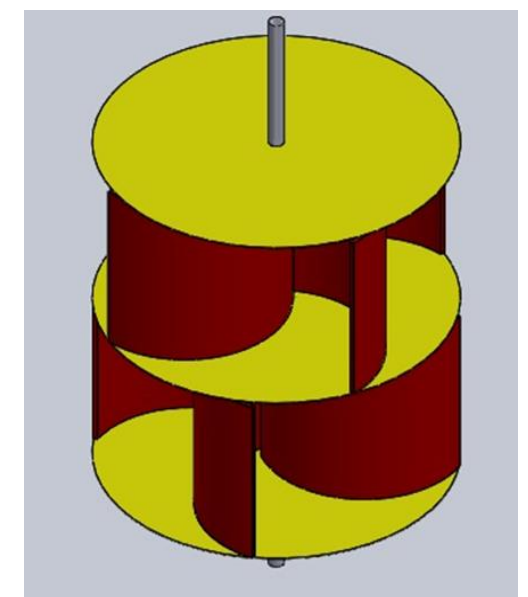

(c)

Fig. 1. Multi-stage Savonius-type rotor: (a) Two-bladed; (b) Three-bladed; (c) Four-bladed

\subsection{Model Domain, Boundary Condition and Solver}

The simulation domain consists of two zones known as a fixed zone and a rotating zone. The fixed zone is taken as the overall calculation area of the simulation. Simultaneously, the rotating zone is the region containing the rotor where the rotor can spin. The rotor is placed at twelve times the radius from the inlet position. While the outlet was positioned at twenty-three times the radius at downwind position, as shown in Figure 2.

The velocity inlet boundary condition is applied at the inlet region, with a constant inlet velocity and a varying tip-speed ratio (TSR) and rotational speed (RPM). While the atmospheric pressure outlet boundary condition is applied at the domain outlet. The blades, top and bottom, and side walls are considered as non-slip wall boundary conditions. The two-equation K-omega shear-stress transport (SST) model was used as the turbulent viscosity model. Meanwhile, the pressure-velocity coupling scheme was adapted for the pressure-based coupled algorithm in the solution technique. 


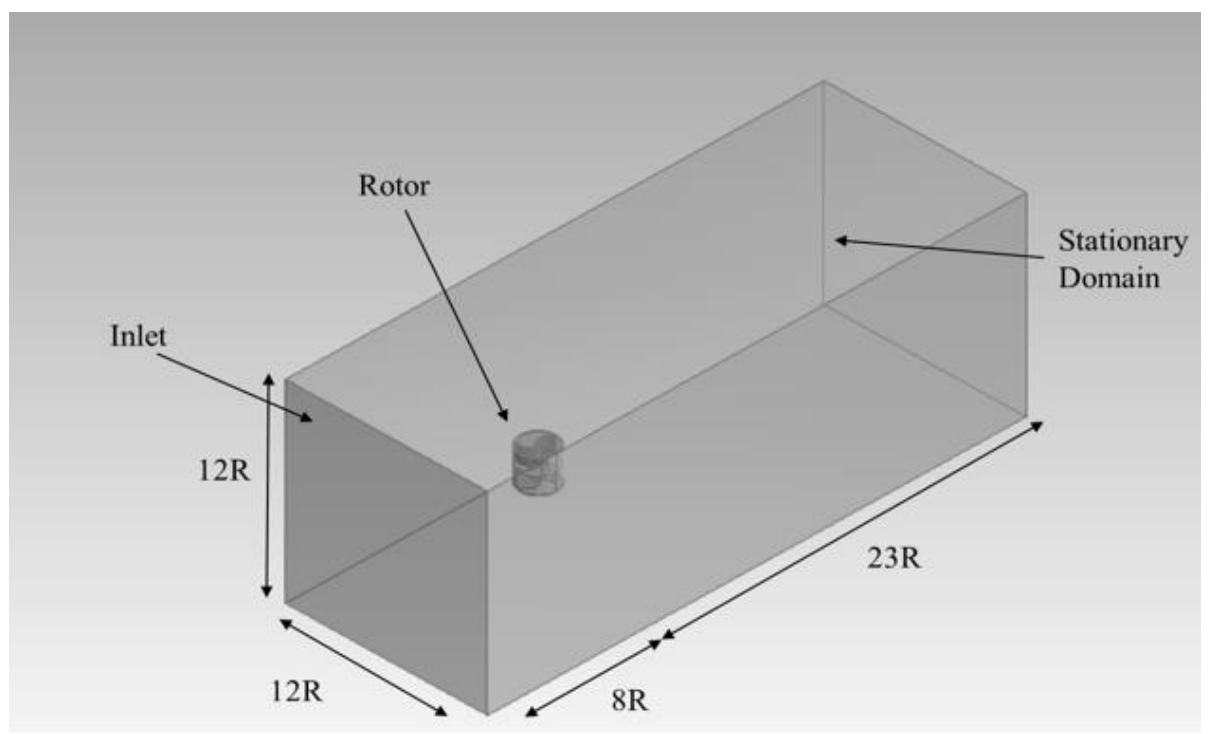

Fig. 2. Simulation domain

\section{Results}

\subsection{Model Validation}

The present simulation study was compared with the experimental study in terms of torque coefficient and power coefficient presented in Wekesa's study [20]. Figure 3 and Figure 4, respectively show the torque coefficient and power coefficient from the present study and previous experimental study. A comparable output between the previous experimental study and the present computational study was observed. The average deviation was $12.85 \%$ which is considered acceptable. Therefore, the current simulation's reliability is proven to be genuine and valid to carry on other simulation processes with the other models.

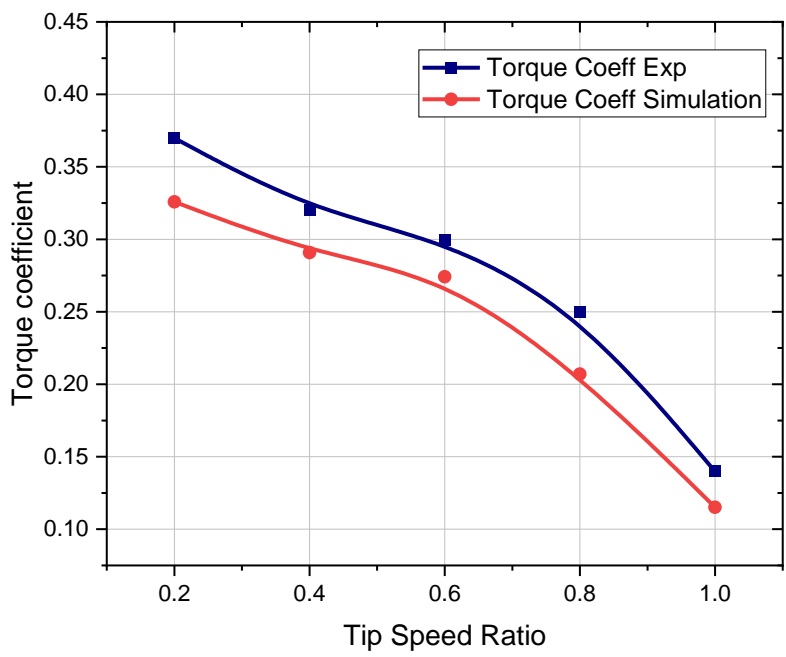

Fig. 3. Torque coefficient of current simulation and previous experimental study

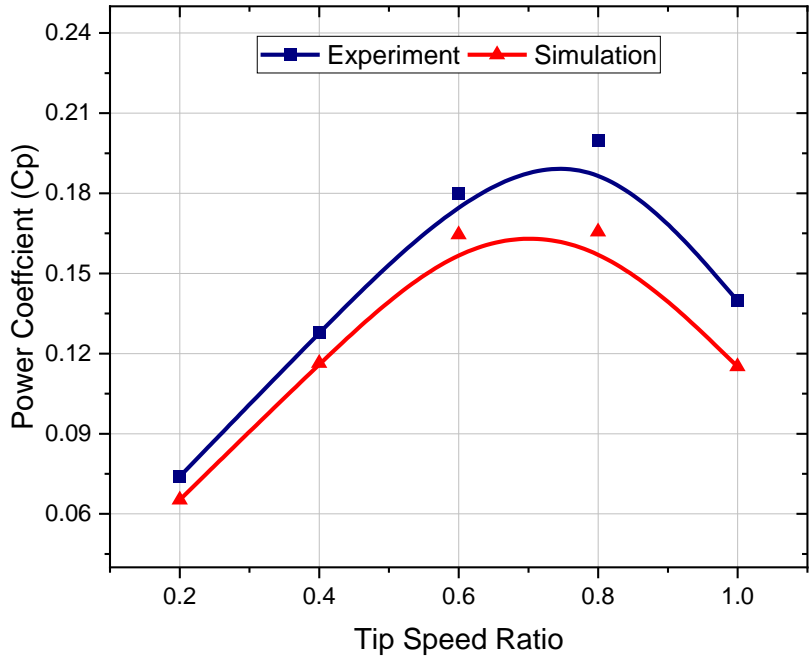

Fig. 4. Power coefficient of current simulation and previous experimental study

\subsection{Performance Evaluation of Predicted Torque and Torque Coefficient}

In this section, the aerodynamics behaviour of the double stage with two, three and four blades Savonius wind turbine regarding the torque output and torque coefficient is discussed. The results of 
all simulation models are presented in terms of torque and torque coefficient against TSR, as shown in Figure 5 and Figure 6, respectively. In general, the current simulation results show the effectiveness of the double stage technique with two, three and four blades Savonius wind turbine.

As shown in Figure 5, the torque output for all designs exhibits a similar trend. The gradual increase in the TSR causes a decrease in the mechanical torque of the rotor. In terms of performance, the two-blade design has the highest torque output compared to the three-blade design and fourblade design. The highest torque of the two-blade occurred at 0.2 TSR with a corresponding maximum torque of $2.61 \mathrm{Nm}$ which is almost double the output of the three-blade design. This shows that the two-blade design has a large self-starting capability and effectiveness at a low speed compared to the three-blade and four-blade design. Meanwhile, the minimum torque output occurs at the highest TSR, with the four-blade design displaying the lowest output compared to the other designs. The lowest torque for the two-blade design is $0.526 \mathrm{Nm}$ at $1 \mathrm{TSR}$. The lowest torque for the four-blade design is $0.124 \mathrm{Nm}$ while for the two-blade and three-blade designs the lowest torques are 0.526 and 0.592 , respectively. Thus, it has been noticed that the increase in the number of the blade in a Savonius rotor with double-stage configuration has a negative impact on the performance of the rotor.

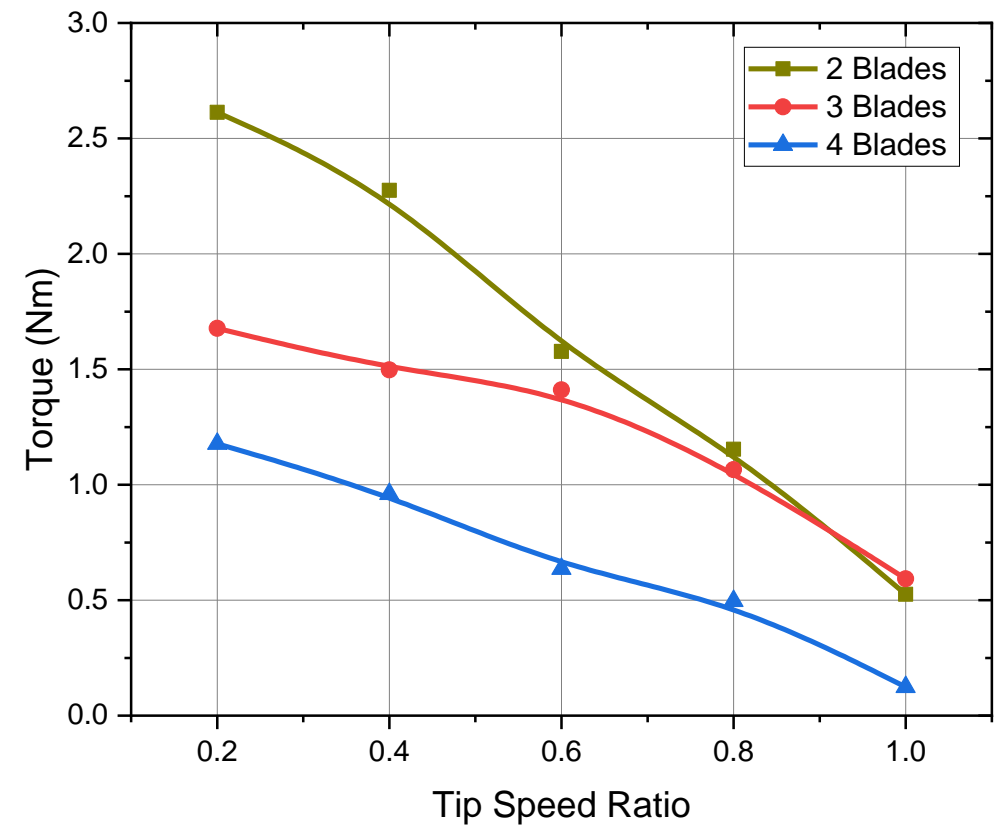

Fig. 5. Torque output against TSR for all models

Figure 6 shows the aerodynamics behaviour of the different number of blades of Savonius rotor designs with respect to torque coefficient. It is observed that the torque coefficient of all models decreases as the tip speed ratio increases. Higher conversion efficiencies exist at low TSRs and lower ones at higher TSRs. Generally, the two-blade design demonstrates higher torque coefficient values compared to the three-blade design and four-blade design. The maximum torque coefficient value obtained was 0.508 at 0.2 TSR. Meanwhile for the lowest torque coefficient value of the two-blade design was 0.102 at 1.0cTSR. The three-blade design followed the two-blade design in terms of performance with the highest conversion efficiency of 0.326 and the four-blade design showed the minimum performance with the value of 0.229 conversion efficiencies. This shows that the four-blade design may have the lowest starting torque capabilities to overcome the self-start difficulties compared to the other two-blade and three-blade designs of the Savonius rotor. 


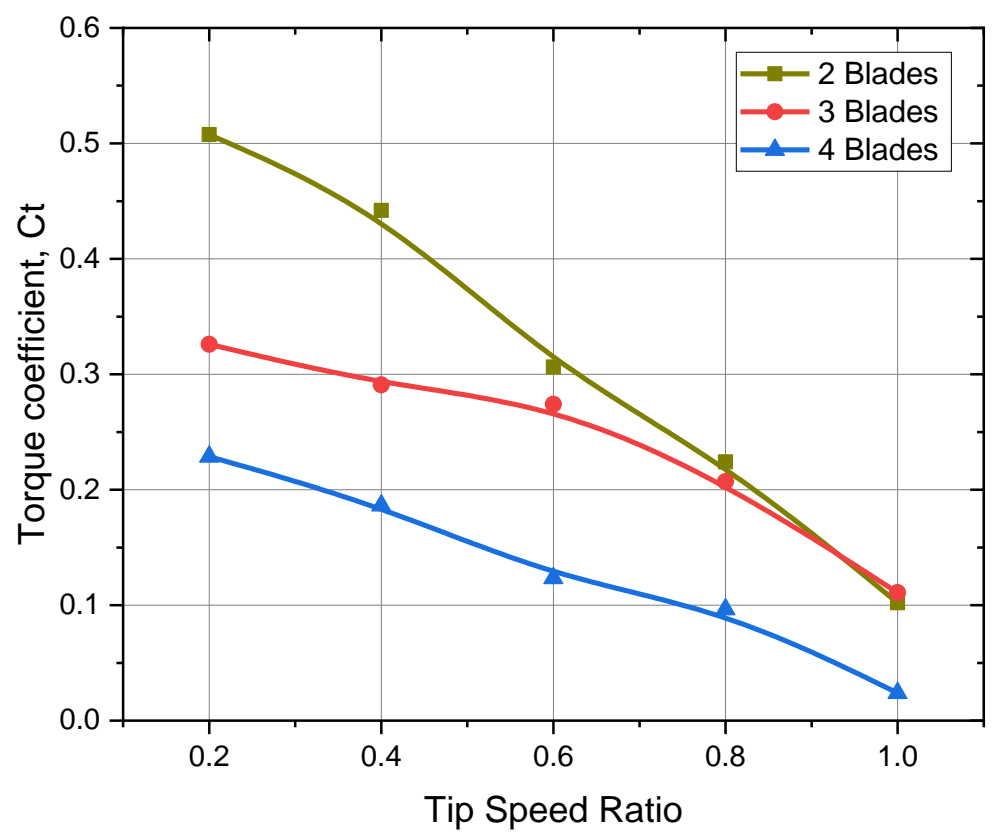

Fig. 6. Torque Coefficient against TSR for all models

\subsection{Performance Evaluation of Predicted Power and Power Coefficient}

This section demonstrates Savonius VAWT's aerodynamic behaviour in relation to the power output and its coefficient through the use of a simulation approach for the two-blade, three-blade and four-blade designs under study. Figure 7 shows the comparison of power output between the different number of blades of the multi-stage Savonius wind turbine. The figure reveals that all the designs possess a similar trend in terms of power output.

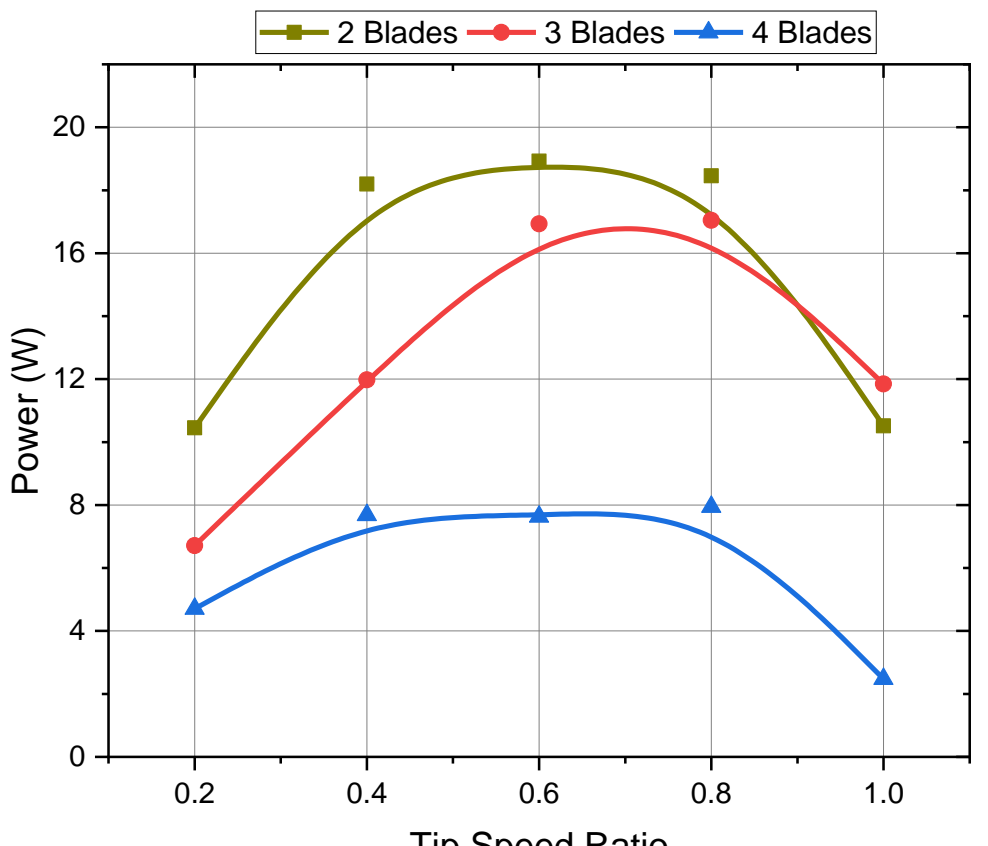

Fig. 7. Power output against TSR for all models

The power output of all rotors increases with the TSR until the optimum TSR or the rated power output of the turbine then it starts to decreases until the cut-out TSR. Moreover, among the three 
designs, the two-blade design demonstrates an overall better performance compared to the threeblade and four-blade designs. For the two-blade model, the highest power is achieved when the TSR $=0.6$ with an equivalent power output of $18.92 \mathrm{~W}$. While for the three-blade and four-blade models, it was achieved at TSR of 0.8 with equivalent power values of $17.05 \mathrm{~W}$ and $8.0 \mathrm{~W}$, respectively. Both of these designs start to decrease beyond the tip speed ratio of 0.8 as compared to 0.6 for the twoblade design. However, the lowest outputs were obtained from the four-blade design followed by the two-blade and the three-blade design.

Figure 8 describes the aerodynamics behavior of the double stage two-blade, three-blade and four-blade designs of the Savonius wind turbine with respect to the power coefficient. The figure shows a comparison of the power coefficient between the different number of blades of the Savonius rotor as a function of TSR. As expected, a similar trend among all designs is observed. The conversion efficiency rises with the TSR until the rated coefficient or the optimum TSR of the model and then decreases until the cut-out TSR, as shown in Figure 8. The rate coefficient or the optimum TSR is the parameter that indicates the highest possible output a wind turbine rotor can possibly generate. Therefore, it is of paramount importance in characterizing the performance of any design. Furthermore, it has been observed that the two-blade rotor has shown the highest power coefficient values, which means that this rotor type has better efficiency compared to the others. The highest power coefficient realized was $18.4 \%$ at the optimum TSR of 0.6. Meanwhile, for both three-blade and four-blade models, the highest value for power coefficient was obtained at 0.8 TSR with corresponding values of $16.6 \%$ and $7.7 \%$, respectively. This means that the two-blade design has the higher power to start up compare to the three-blade and four-blade models. However, although the multistage might have improved the performance of the Savonius rotor in general, the four-blade model has shown the least conversion efficiencies compared to the other models with multi-stage configurations.

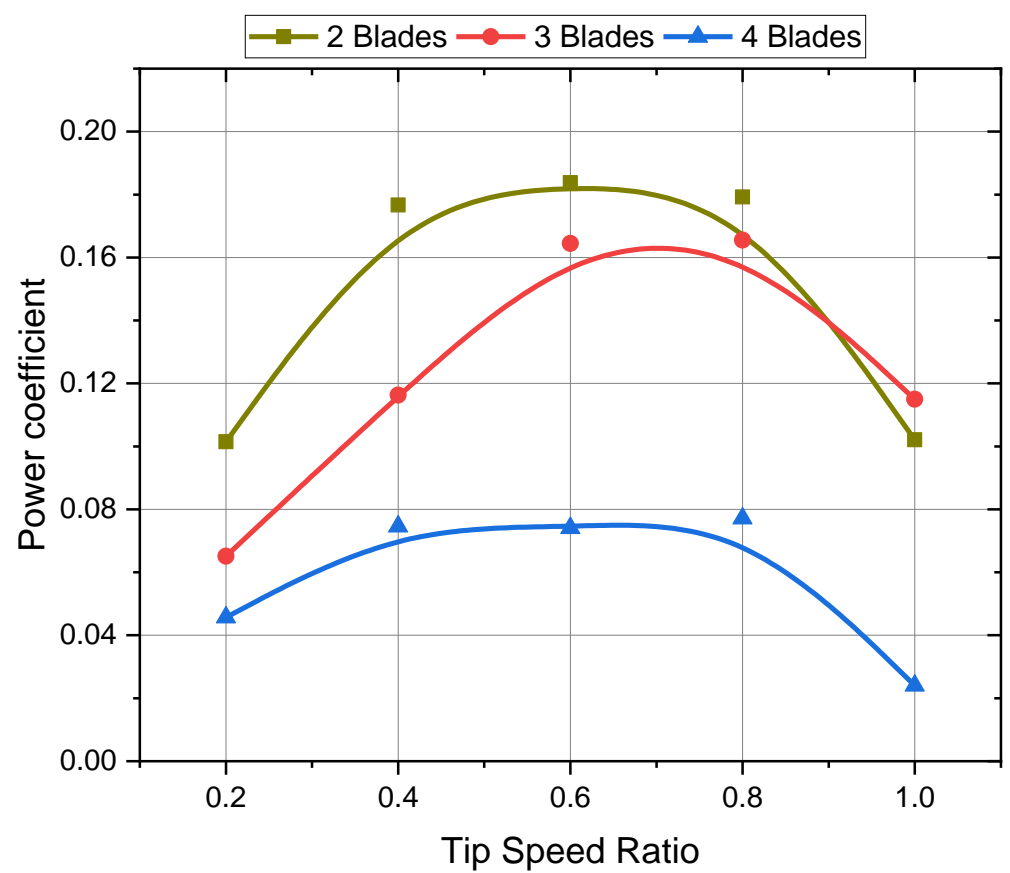

Fig. 8. Power coefficient against TSR for all models

The pressure contour, as shown in Figure 9 illustrates that the incoming blade has a higher pressure compared to the other returning blade at the surface of the blade. It has a higher pressure on the concave side of the wind blade and on the convex side, which shows that the pressure is low. 
This is because the incoming wind attacks the concave side first then only the rotor rotates according to the rotor direction. The velocity distribution around the model has the highest tangential velocity at the tip of blades while the lowest is at the center of rotation, as shown in Figure 10. Besides, the velocity contour in the middle of the rotor is lower compare to the outer of the blade.
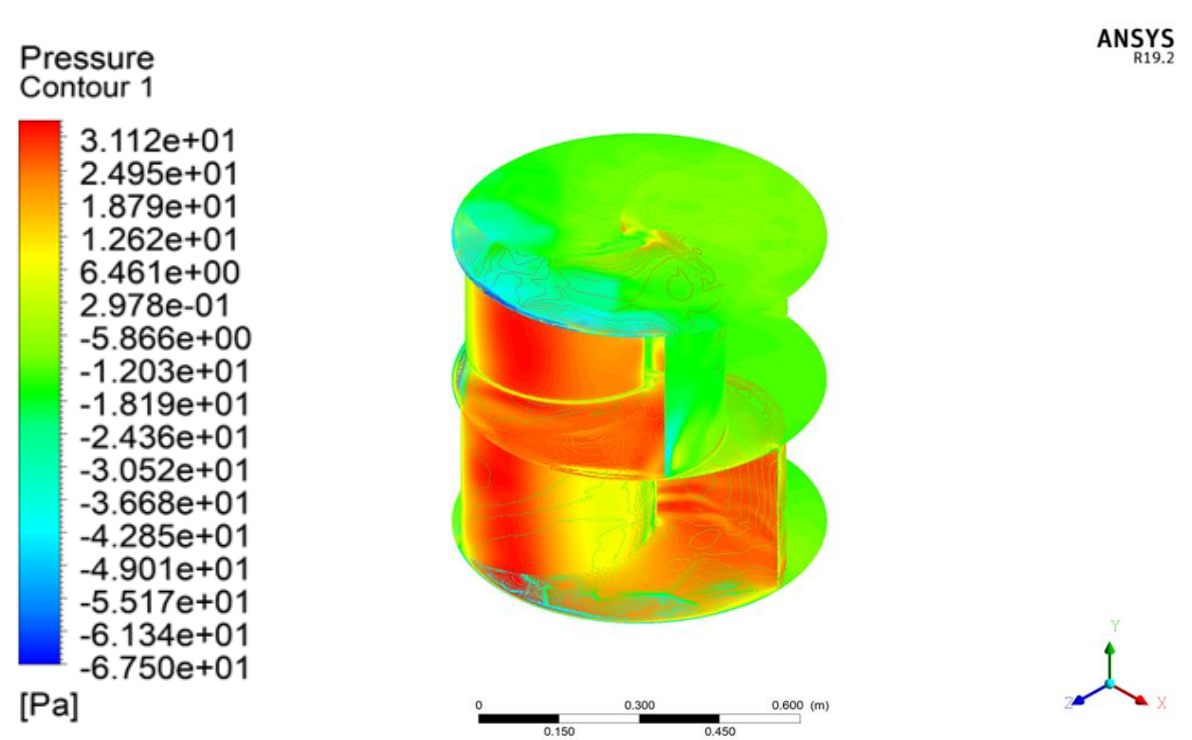

Fig. 9. Pressure contour for three blades at a tip-speed ratio of 0.2
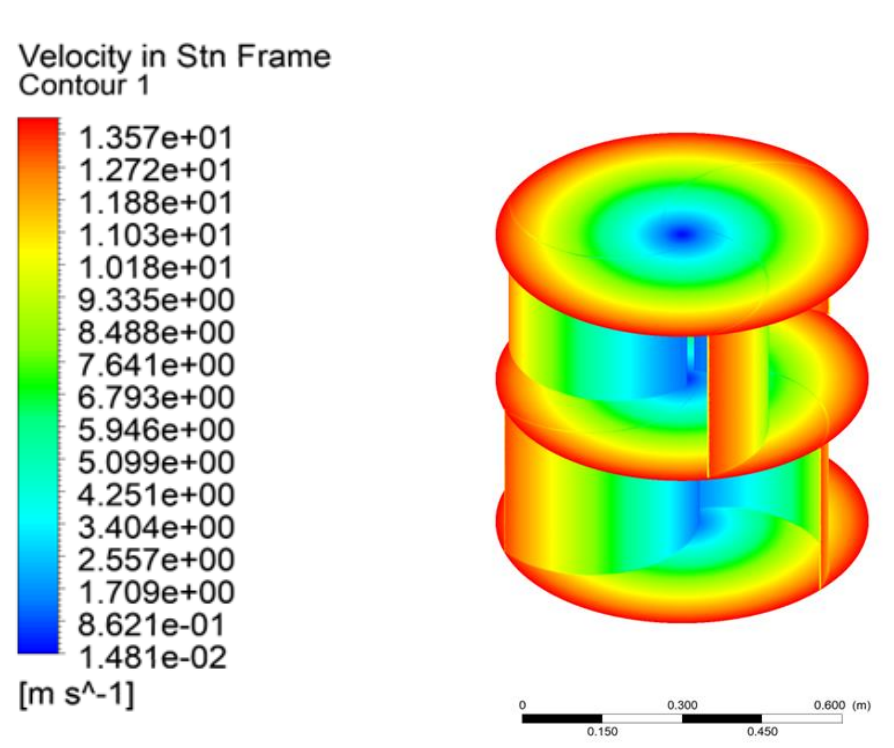

ANSYS Contour 1

Fig. 10. Velocity contour for three blades at a tip-speed ratio of 0.2

\section{Conclusions}

In the present paper, a simulation study based on three-dimensional computational fluid dynamics (CFD) models for double-stage Savonius wind turbine rotors are considered. the main purpose of this study was to examine the effectiveness of the double-stage technique in increasing the efficiency while overcoming the inherent low inefficiency of the Savonius rotor. Three simulation models are developed on the double-stage model based on a different number of blades. These models are tested in terms of torque, power, torque coefficient and power coefficient. The computational study involved the use of the K-omega SST as the turbulent model. 
The simulation results have shown that the double-stage technique was capable of enhancing the performance of the Savonius rotor. Moreover, it was observed that more blades on a double-stage rotor have a negative effect on the performance of the Savonius rotor in terms of both torque efficiency and power efficiency. The highest conversion efficiency in terms of power among all models occurs at the TSR of 0.6 with a corresponding maximum power coefficient of $18.4 \%$. Comparing the three models, it was found that the two-blade model of the double-stage produced more torque and power output compared to the other three-blade and four-blade models of the double-stage Savonius rotor. The maximum power and torque achieved by the two-blade model were $18.92 \mathrm{~W}$ and $2.61 \mathrm{Nm}$, respectively. This simulation study was validated by previous results with an overall average percentage of relative error of $12.85 \%$.

\section{Acknowledgement}

The authors would like to acknowledge the Publisher's Office, Universiti Tun Hussein Onn Malaysia for the financial support under Publishing Fund (E15216) and Industrial Grant (M002).

\section{References}

[1] Garver Jr, John B. "National Geographic Society." The American Cartographer 14, no. 3 (1987): $237-240$. https://doi.org/10.1559/152304087783875921

[2] Perera, Frederica. "Pollution from fossil-fuel combustion is the leading environmental threat to global pediatric health and equity: solutions exist." International journal of environmental research and public health 15 , no. 1 (2018): 16. https://doi.org/10.3390/ijerph15010016

[3] Jaat, Norrizam, Amir Khalid, Norrizal Mustaffa, Fathul Hakim Zulkifli, Norshuhaila Mohamed, Ridwan Saputra Nursal Sunar, Mahmod Abd Hakim Mohamad, and Djamal Didane. "Analysis of injection pressure and high ambient density of biodiesel spray using computational fluid dynamics." CFD Letters 11, no. 1 (2019): 28-39.

[4] Hassane, Abdelhamid Issa, Djamal Hissein Didane, Abakar Mahamat Tahir, and Jean-Marie Hauglustaine. "Wind and Solar Assessment in the Sahelian Zone of Chad." International Journal of Integrated Engineering 10, no. 8 (2018): 164-174. https://doi.org/10.30880/ijie.2018.10.08.026

[5] Alquraishi, Balasem Abdulameer, Nor Zelawati Asmuin, Sofian Mohd, Wisam A. Abd Al-Wahid, and Akmal Nizam Mohammed. "Review on Diffuser Augmented Wind Turbine (DAWT)." International Journal of Integrated Engineering 11, no. 1 (2019). https://doi.org/10.30880/ijie.2019.11.01.021

[6] Bhatia, S. C., ed. Advanced renewable energy systems, (Part 1 and 2). CRC Press, 2014. https://doi.org/10.1201/b18242

[7] Didane, Djamal Hissein, Muhammad Amir Zafran Saipul Anuar, Mohd Faizal Mohideen Batcha, Kamil Abdullah, Mas Fawzi Mohd Ali, and Akmal Nizam Mohammed. "Simulation Study on the Performance of a Counter-rotating Savonius Vertical Axis Wind Turbine." CFD Letters 12, no. 4 (2020): 1-11. https://doi.org/10.37934/cfdl.12.4.111

[8] Didane, D. H., S. Mohd, Z. Subari, N. Rosly, MF Abdul Ghafir, and MF Mohd Masrom. "An aerodynamic performance analysis of a perforated wind turbine blade." In IOP Conference Series: Materials Science and Engineering, vol. 160, no. 1, p. 012039. IOP Publishing, 2016. https://doi.org/10.1088/1757-899X/160/1/012039

[9] Al-Ghriybah, Mohanad, Mohd Fadhli Zulkafli, Djamal Hissein Didane, and Sofian Mohd. "Review of the recent power augmentation techniques for the Savonius wind turbines." Journal of Advanced Research in Fluid Mechanics and Thermal Sciences 60, no. 1 (2019): 71-84.

[10] Hyams, M. A. "Wind energy in the built environment." In Metropolitan Sustainability, pp. 457-499. Woodhead Publishing, 2012. https://doi.org/10.1533/9780857096463.3.457

[11] Lee, Jae-Hoon, Young-Tae Lee, and Hee-Chang Lim. "Effect of twist angle on the performance of Savonius wind turbine." Renewable Energy 89 (2016): 231-244. https://doi.org/10.1016/i.renene.2015.12.012

[12] Zeman, Frank, ed. Metropolitan sustainability: Understanding and improving the urban environment. Elsevier, 2012. https://doi.org/10.1533/9780857096463

[13] Wenehenubun, Frederikus, Andy Saputra, and Hadi Sutanto. "An experimental study on the performance of Savonius wind turbines related with the number of blades." Energy procedia 68 (2015): $297-304$. https://doi.org/10.1016/j.egypro.2015.03.259

[14] Ali, Mohammed Hadi. "Experimental comparison study for Savonius wind turbine of two \& three blades at low wind speed." International Journal of Modern Engineering Research (IJMER) 3, no. 5 (2013): 2978-2986. 
[15] Saha, U. K., and M. Jaya Rajkumar. "On the performance analysis of Savonius rotor with twisted blades." Renewable energy 31, no. 11 (2006): 1776-1788. https://doi.org/10.1016/i.renene.2005.08.030

[16] Kumar, Anuj, and R. P. Saini. "Performance parameters of Savonius type hydrokinetic turbine-A Review." Renewable and Sustainable Energy Reviews $64 \quad$ (2016): $289-310$. https://doi.org/10.1016/i.rser.2016.06.005

[17] Al-Ghriybah, Mohanad, Mohd Fadhli Zulkafli, Djamal Hissein Didane, and Sofian Mohd. "Performance of the Savonius Wind Rotor with Two Inner Blades at Low Tip Speed Ratio." CFD Letters 12, no. 3 (2020): 11-21. https://doi.org/10.37934/cfdl.12.3.1121

[18] Didane, Djamal Hissein, Siti Masyafikah Maksud, Mohd Fadhli Zulkafli, Nurhayati Rosly, Syariful Syafiq Shamsudin, and Amir Khalid. "Performance investigation of a small Savonius-Darrius counter-rotating vertical-axis wind turbine." International Journal of Energy Research 44, no. 12 (2020): 9309-9316. https://doi.org/10.1002/er.4874

[19] Didane, D. H., S. M. Maksud, M. F. Zulkafli, N. Rosly, S. S. Shamsudin, and A. Khalid. "Experimental Study on the Performance of a Savonius-Darrius Counter-Rotating Vertical Axis Wind Turbine." In IOP Conference Series: Earth and Environmental Science, vol. 268, no. 1, p. 012060. IOP Publishing, 2019. https://doi.org/10.1088/1755$1315 / 268 / 1 / 012060$

[20] Wekesa, David Wafula, Cong Wang, Yingjie Wei, and Weidong Zhu. "Experimental and numerical study of turbulence effect on aerodynamic performance of a small-scale vertical axis wind turbine." Journal of Wind Engineering and Industrial Aerodynamics 157 (2016): 1-14. https://doi.org/10.1016/i.jweia.2016.07.018 